\title{
Black Shank of Tobacco in Connecticut Fields
}

By G.S.Taylor, J.L.McIntyre,P.E.Waggoner

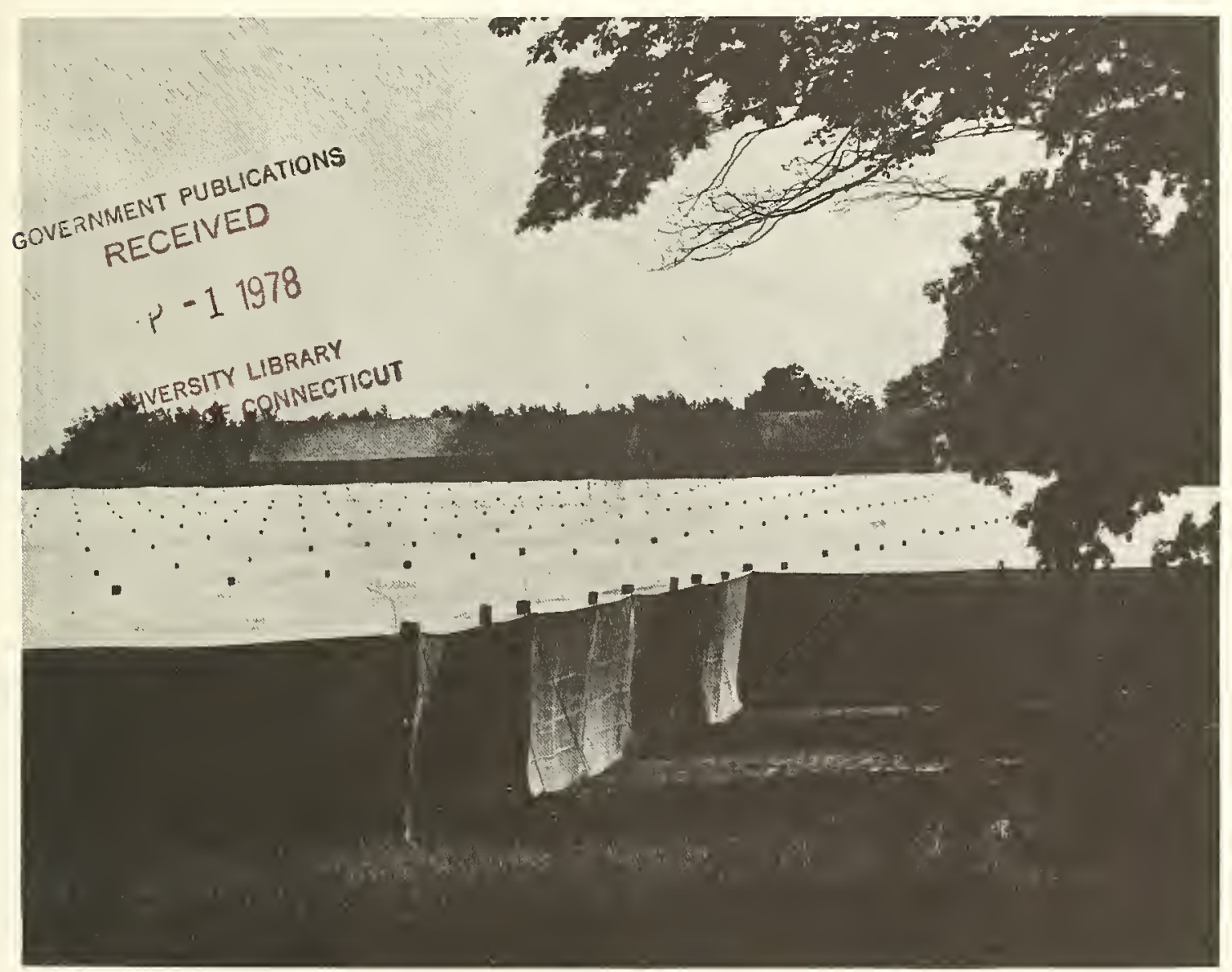




\section{Digitized by the Internet Archive in 2011 with funding from}

LYRASIS members and Sloan Foundation 


\section{Black Shank of Tobacco}

\section{in Connecticut Fields}

\section{By G.S.Taylor, J.L.McIntyre, P.E. Waggoner}

In mid-July, 1973, a grower of shade tobacco discovered wilting plants with stems blackened near the soil. Although the wilting plants were scattered, they were most frequently found in low places where water drained slowly (Fig. 1). The grower, who had seen similar symptoms on blackshank-diseased tobacco in North Carolina, brought the wilted plants to the attention of a Station scientist. Pieces of diseased stem kept in water overnight developed sporangia

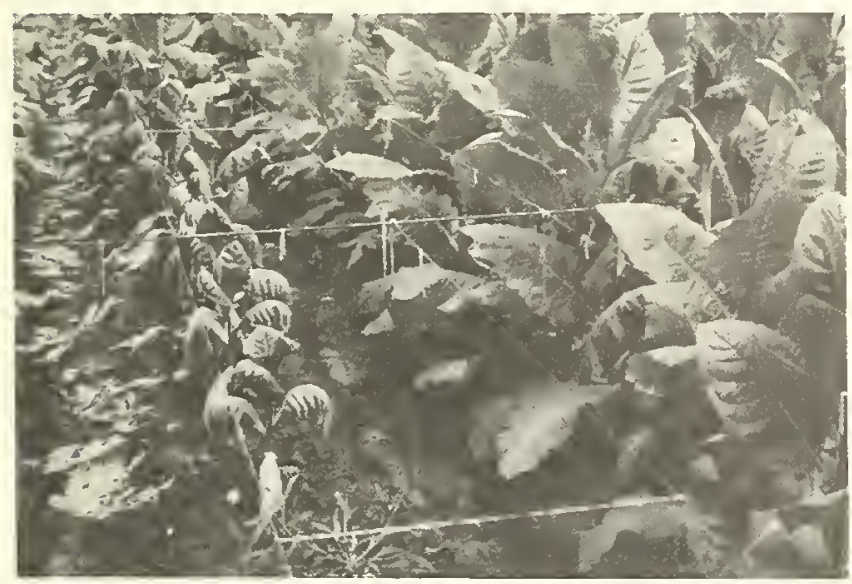

Fig. 1. Black shank disease on shade tobacco in Connecticut. MidJuly-note dying plants on left and wilted plant among still healthy plants in right hand row. of the fungus Phytophthora parasitica, and we knew that black shank, which had not been reported north of Pennsylvania, had reached Connecticut (Walton and Rich, 1974).

The black shank pathogen, Phytophthora parasitica (Dast) var. nicotianae (B. de Haan) Tucker, can grow throughout the tobacco plant Nicotiana tabacum L., but generally attacks the lower stem and roots. The typical blackening of the lower stem gives the disease its name, and the decay of the stem and roots causes the wilting of leaves. Sporangia form rapidly in water in the upper soil. Each sporangium germinates to form about eight zoospores that swim in water; the zoospores are carried to other tobacco plants, spreading the disease. The fungus is encouraged by moisture and warmth. Since Phytophthora parasitica var. nicotianae is found in warm climates around the world and has an optimum temperature for growth of about $30^{\circ} \mathrm{C}$, we had thought Phytophthora parasitica was restricted to the warmer, more southerly states by the Connecticut weather.

Our first question was, "How had this Southern pathogen reached Connecticut?" It is known that it can be moved in soil, and hence it could have reached Connecticut in many ways: on the wheels of autos, on irrigation pipe, on plants, or even on used shade cloth. No clear evidence of which route was taken has been established.

The next question was, "Would the Southern pathogen be killed by the first cold winter or had a new race arisen, and we would have years of black shank?" We soon learned that a specimen from Connecticut growing in oatmeal agar survived quick freezing to $-23^{\circ} \mathrm{C}$ for 12 days or for a 
month at $-2^{\circ} \mathrm{C}$. The fungus also survived in infested soil exposed to four cycles of $6^{\circ} \mathrm{C}$ for 4 days and $-12^{\circ} \mathrm{C}$ for 4 days (Taylor, 1975). During the ensuing winter, soil outdoors in the black-shank-infested field did not freeze deeper than $10 \mathrm{~cm}$.

During the summer of 1974 , black shank reappeared on three fields and appeared for the. first time on seven other fields (Taylor, 1975). In 1975, the disease was found in 18 fields. The pattern of spread is mapped in Fig. 2. Planting of resistant varieties and use of non-infested fields reduced disease incidence drastically in 1976 and to only a few fields in 1977. Black shank has appeared only on fields of a cooperating group of growers who raise similar tobacco cultivars and sometimes exchange equipment and workers. Evidently, Phytophthora parasitica var. nicotianae had arrived in Connecticut to stay, at least for a while, and a coldresistant strain was suspected.

The tasks were then to learn whether a cold-resistant strain in fact existed, to observe its response to the field environment, and to learn how to control it with chemicals or resistant varieties.

\section{RESPONSE TO COLD OF RACES 0 AND 1, AND OF CONNECTICUT ISOLATES.}

\section{Materials and methods.}

The following isolates of $P$. parasitica var. nicotianae were examined: race 0 (isolate 1587 , from $\mathrm{C}$. Litton, University of Kentucky, Lexington KY; isolate 1189-A-2, from J. Apple, North Carolina State University, Raleigh, NC; isolates 1189-A-3, A-10-2, M-16 (9), and D-Barrow-1, from G. Lucas, North Carolina State University, Raleigh, NC; isolates 42 and 230, from R. Flowers, Georgia Coastal Plains Experiment Station, Tifton, GA; and isolates M-15E, M-15H, and M-15I from unknown source); race 1 (isolate 1668-1 from C. Litton; isolate 1452-1-2-2 from J. Apple; isolate 85-B-1-75 from G. Lucas; isolates 43 and 228 from R. Flowers; and isolates $\mathrm{M}-15 \mathrm{~F}$ and $\mathrm{M}-15 \mathrm{G}$ from unknown source); and Connecticut (isolates M-15J, K, M, O, P, S, $\hat{\mathrm{T}}, \mathrm{U}, \mathrm{V}$, and $\mathrm{W}$ collected from infected tobacco plants during the summers of 1973,1974 , and 1975). Soil was infested with pooled race 0 , pooled race 1 , and pooled Connecticut isolates.

Tolerances of these isolates to simulated winter temperatures in Connecticut were determined in the following manner. Cultures were grown in nutrient broth $(100 \mathrm{ml}$ per 500 $\mathrm{ml}$ Erlenmeyer flask, five flasks per isolate) at $25^{\circ} \mathrm{C}$ in the dark. After seven days incubation, mycelium was harvested by filtration, washed with sterile distilled water, and ground with $50 \mathrm{ml}$ of sterile distilled water in a Waring blender. This suspension was poured into $500 \mathrm{~g}$ of steam-sterilized soil. The soil was air-dried, and $5 \mathrm{~g}$ samples were enclosed in 10.5-x-11.5-cm plastic bags. The samples were maintained at $22^{\circ} \mathrm{C}$ or $-10^{\circ} \mathrm{C}$ in the dark, or cycled between 22 and $-10^{\circ} \mathrm{C}$ (one cycle is seven days at $22^{\circ} \mathrm{C}$ and seven days at $-10^{\circ} \mathrm{C}$ ). At the beginning of the experiment and after each cycle, $0.1 \mathrm{~g}$ of soil was removed from each bag and placed in a petri dish, and another sample was inserted in an apple (Campbell, 1949).

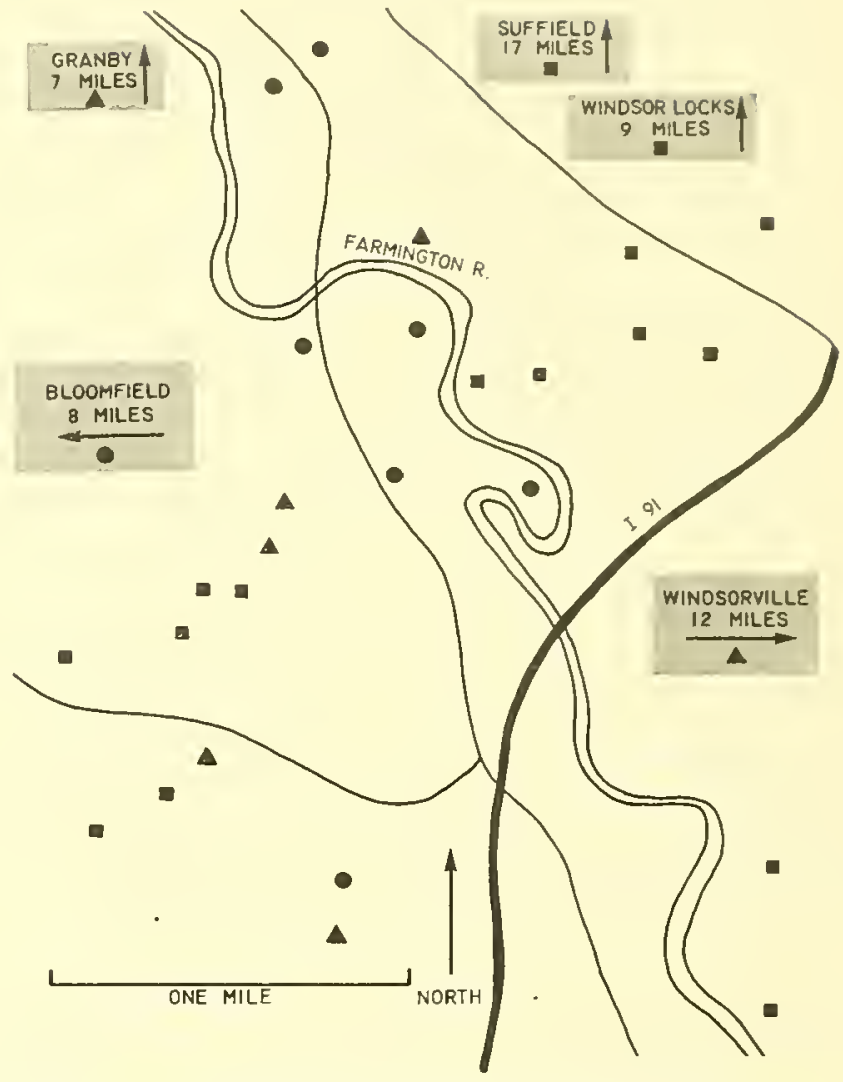

Fig 2. Location of tobacco fields where at least some black shank was found for the first time in 1973 (circles), 1974 (triangles), and 1975 (squares). Insets show locations other than Windsor and approximate road miles from Windsor.

The soil in the dish was flooded with $10 \mathrm{ml}$ of sterile distilled water. A $1-\mathrm{cm}$ disk was cut from a leaf of the highly susceptible tobacco cultivar WS-117, the disk was floated on the water, and the dish incubated in the dark at $30^{\circ} \mathrm{C}$. Two days later, the leaf disk was examined for sporangia. This method resembles one introduced by Grimm \& Alexander (1973).

The inoculated apple was incubated at $25^{\circ} \mathrm{C}$ in the dark, and if rotting occurred, tissue was removed from the apple, placed on medium for isolation of Phytophthora (Tsao and Ocana, 1969), and observed for the presence of the pathogen.

\section{Results.}

Both the floating leaves and the apples produced the same results. Survival after a temperature treatment is shown by + in Table 1 , and non-survival is shown by -. All isolates survived at $22^{\circ} \mathrm{C}$, but only the Connecticut one survived $-10^{\circ} \mathrm{C}$. All isolates survived one or two cycles of cold, but only the Connecticut one survived three or four cycles.

Clearly, the Connecticut isolates are more tolerant of cold than races 0 and 1 from the South. Thus, the races, which are biochemically different and can be differentiated by resistant varieties (Mclntyre \& Taylor, 1978), are also different in susceptibility to cold. Because of these differences, the pathogen labeled "Connecticut" in Table 1 is now called "race 3" (Mclntyre \& Taylor, 1978). 
Table 1. Survival in soil of Connecticut isolates of Phytophthora parasitica var. nicotianac after six temperature treatments. Survival is shown by + and non-survival by -.

\begin{tabular}{lccc}
\hline Temperature treatments & Race & $\frac{\text { Isolates }}{\text { Race l }}$ & Connecricut \\
\hline $22^{\circ} \mathrm{C}$ (continuous) & $\frac{+}{+}$ & + & + \\
$-10^{\circ} \mathrm{C}$ (continuous) & - & - & + \\
Cycled ${ }^{a}$ Once & + & + & + \\
$\quad$ Twice & + & + & + \\
$\quad$ 3-Times & - & - & + \\
4-Times & - & - & + \\
a One cycle was 7 days at $22^{\circ} \mathrm{C}$ followed by 7 days at $-10^{\circ} \mathrm{C}$. \\
\hline
\end{tabular}

\section{RESPONSE TO SOIL MOISTURE IN THE FIELD.}

\section{Materials and methods.}

On May 22, 1976, 50 breeding lines of shade tobacco were planted in Windsor on 10 "bents" of a field where black shank had reappeared annually since 1974. A bent is about $10 \times 10$ meters or $1 / 100$ hectare. The field, $20 \times 50 \mathrm{~m}$, sloped gently from two opposite corners toward a broad depression that crossed diagonally and drained surface water gently toward the lowest comer of the field (Fig. 3). The soil on the slopes was well-drained Hadley silt Joam and the soil in the depression was moderately well-drained Winowski silt loam with a gray surface that grades into a mottled gray and brown subsoil. Ten $\mathrm{m}$ of row were planted with each variety in two randomized blocks. There were from 25 to 30 plants per row.

At about weekly intervals during July and August the incidence of black shank was observed, and diseased plants were pulled and laid in the furrow. On October 8 , the total number of plants that had become diseased during the season was determined for each 10 meters of row. On December 1, elevations were measured by transit at 3.3 meter intervals across the rows and 6.6 meter intervals along the rows for each $10 \times 10 \mathrm{~m}$ bent. Mean elevations were determined for each 10-meter row.

Results.

The greatest incidence of disease was in the depression that passes diagonally through the field (Fig. 3). This confirms the well-known favorability of water and moist soil for the disease and its spread (Lucas, 1965). This heterogeneity of elevation and moisture interferes with comparisons among varieties to determine their resistance, and we shall later remove this confusing effect.

\section{CONTROL USING CHEMICALS}

Soil fumigants have been tested in Southern states where black shank has long occurred (e.g., Todd, 1973). The effective treatments contain methyl isothiocyanates or chlorpicrin.

In Connecticut, Taylor, et al. (1975) tested commercial soil fumigants against the pathogen in the laboratory and found that only those containing chloropicrin or methyl isothiocyanate appeared effective. In their field tests, two materials DD 30 and DD-MENCS at a rate of 30 gallons per acre $(280 \mathrm{l} / \mathrm{ha})$ resulted in only $8 \%$ to $9 \%$ diseased plants vs. $45 \%$ discased plants on the untreated plots.

Generally, chloropicrin decreases the quality of wrapper tobacco by producing darker, mottled leaves. Therefore, we tested fumigants containing chloropicrin or methyl isothiocyanates for their effect upon quality.

Materials and methods.

A field that had not grown tobacco for 10 years was plowed and harrowed in the fall of 1973 before fumigants were applied. The fumigants were DD 15 (a mixture of $85 \%$ dichloropropene-dichloropropane and related $\mathrm{C} 3$ hydrocarbons [DD] and 15\% chloropicrin), DD 30 (70\% DD plus 30\% chloropicrin), EDB 15 (a mixture of $85 \%$ ethylenedibromide [EDB] and 15\% chloropicrin), EDB 30 (70\% EDB plus $30 \%$ chloropicrin), and DD-MENCS (a mixture of $80 \%$ DD and $20 \%$ methyl isothiocyanate).

During October, 1973, the fumigants were injected into the soil at a rate of $280 \mathrm{l} / \mathrm{ha}$ at a depth of $20 \mathrm{~cm}$ on $25 \mathrm{~cm}$ centers. The experimental design was three randomized blocks of six 10-by-50 m plots.

In the spring of 1974 , the field was fertilized with 4000 $\mathrm{kg} / \mathrm{ha}$ of 6-3-6 cottonseed-meal-base tobacco fertilizer. In late May, the highly susceptible cultivar WS-117 was planted with rows in the same direction as the fumigation. On July 22, and about 2 week intervals thereafter until August 29, samples of 88 leaves from each plot were picked, cured, and processed by the grower. The color of the processed leaves was evaluated by ranking the six samples from a date and a block from 1 for darkest, to 6 for lightest color. Thus, for each date and block (or replicate) there was a sample rated 1 and a sample rated 6 . In addition, the individual leaves from the August 1 harvest were sorted into the commercial grades used by the grower. These were combined into "best", "average", and "poor", and the percentage of the weight (yield) in each class was determined. Plant height to tip of tallest leaf was measured on June 24.

Results

Generally, height of plant was increased by fumigation, especially by DD (Table 2). The plants grown on plots treated with the four fumigants containing chloropicrin

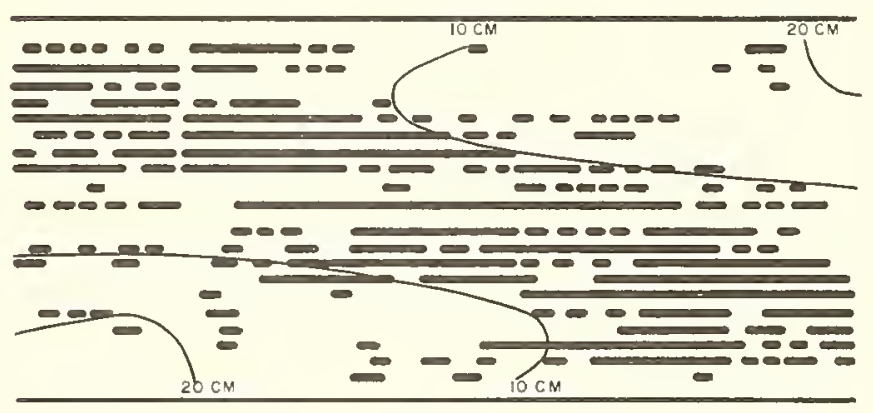

Fig. 3. Incidence of black shank and elevation of soil in a field of shade tobacco. Rows extend $50 \mathrm{~m}$ from left to right in the figure. The field is $20 \mathrm{~m}$ wide. The depression that extends diagonally across the field lies between the two $10-\mathrm{cm}$ contours drawn on the figure. A diseased plant is shown by a short, wide segment of a row and a series of diseased plants is shown by a continuous, wide segment. 
produced darker leaves on nearly every date and in every replicate (Table 2). The treatment without chloropicrin (DD-MENCS) did not cause darker leaves.

Table 2. Effect of soil fumigants upon plant height and color of tobacco leaves.

\begin{tabular}{|c|c|c|c|c|c|c|}
\hline \multirow{3}{*}{$\frac{\text { Fumigant }}{\text { untreated }}$} & \multirow{2}{*}{$\frac{\text { Height, cm }}{6 / 24}$} & \multicolumn{5}{|c|}{ Rank of color ${ }^{1}$} \\
\hline & & $7 \longdiv { 2 2 }$ & $.8 / 1$ & $8 / 14$ & $8 \sqrt{29}$ & Average \\
\hline & $30 \quad c^{2}$ & $\overline{5.3}$ & $\overline{5.0}$ & 4.3 & 4.3 & 4.7 \\
\hline DD-MENCS & 32 & 5.0 & 5.0 & 5.0 & 5.7 & 5.2 \\
\hline EDB 15 & 37 & 2.7 & 2.7 & 4.0 & 2.0 & 2.8 \\
\hline DD 15 & 35 & 2.7 & 3.7 & 3.0 & 4.7 & 3.5 \\
\hline EDB 30 & abc & 3.7 & 3.3 & 1.7 & 2.7 & 2.8 \\
\hline DD 30 & 38 & 1.7 & 1.3 & 1.7 & 1.7 & 1.6 \\
\hline
\end{tabular}

1 Color was ranked within a date and replicate from 1 for darkest to 6 for lightest. Figure shown is mean rank of the three replicates.

2 Means with the same letter are not significantly different according to Duncan's multiple range test.

The yield was also increased by fumigation (Table 3 ). The commercial grading, however, gave different results from color ranking. That is, DD-MENCS decreased commercial quality (Table 3), although it did not darken the leaves (Table 2). Therefore, one has to conclude that DD-MENCS harmed the other components of commercial quality, such as uniformity of color or flexibility.

Table 3. Effect of soil fumigants upon commercial quality of tobacco leaves harvested on August 1.

\begin{tabular}{|c|c|c|c|c|}
\hline \multirow[b]{2}{*}{ Fumigant } & \multirow[b]{2}{*}{$\begin{array}{l}\text { Yield, } \\
\mathrm{kg} / \mathrm{ha} / \mathrm{yr}\end{array}$} & \multirow[b]{2}{*}{ Best } & \multicolumn{2}{|c|}{ Percentage of weight } \\
\hline & & & Average & Poor \\
\hline Untreated & 1870 & $\overline{80}$ & 19 & $\overline{0.3}$ \\
\hline DD-MENCS & 1990 & 66 & 34 & 0.6 \\
\hline EDB 15 & 2010 & 61 & 37 & 2.5 \\
\hline DD 15 & 2100 & 64 & 35 & 1.2 \\
\hline EDB 30 & 2060 & 60 & 35 & 2.6 \\
\hline DD 30 & 2210 & 53 & 43 & 2.0 \\
\hline
\end{tabular}

\section{RESISTANCE IN SHADE TOBACCO.}

\section{Seedlings in the laboratory.}

Tests of resistance of large plants in infested fields have the disadvantage of variation among seasons and also of variation among places in the field caused by differences in either inoculum or soil. A method for determining resistance of small seedlings in the laboratory allows greater control of the environment and saves time and space. Tests for resistance in seedlings have been devised (e.g., Litton, et al., 1970). Here we modified the rapid method of Mclntyre and Taylor (1976), tested seedlings of several tobacco lines and will later compare the results with the performance of mature plants in Phytophthora-infested fields.

MATERIALS AND METHODS. Seedlings were grown in pans containing sterilized sand or a sterilized mixture of equal parts of peat, perlite, and sand. Seedlings with 4 to 5 leaves were prepared by gently rinsing in tapwater until the roots were free of most particles. Ten seedlings were then arranged in a circle with roots to the center and resting on a moist paper in the bottom of a $100 \mathrm{~mm} \times 20 \mathrm{~mm}$ deep plastic petri dish.
Inoculum was prepared by the method of Taylor (1978). A $45-\mathrm{mm}$ diameter disk of rayon cloth (Handiwipe) was placed on the surface of lima bean agar in a $60-\mathrm{mm}$ petri dish. Phytophthora parasitica var. nicotianae was transferred to the center of the disk. After five days at $28-$ to $30^{\circ} \mathrm{C}$, the cloth and attached mycelium was removed, rinsed in deionized water, and placed on $3 \%$ water agar in $100-\mathrm{mm}$ petri dishes. After three- to five days at $28-$ to $30^{\circ} \mathrm{C}$ in the dark, these cultures had produced zoosporangia. Zoospores were released by chilling the cultures to $4^{\circ} \mathrm{C}$ for $20 \mathrm{~min}$, adding water and holding at $20^{\circ} \mathrm{C}$ for an hour. Concentration of the resulting spore suspension was adjusted to 5000 zoospores per $\mathrm{ml}$. Swimming zoospores congregate near the water șurface, thus reducing the uniformity of subsamples. A more uniform inoculum was obtained by shaking the suspension vigorously for a few minutes to stop the swimming (Goode, 1956) and stirring the suspension of encysted zoospores while samples were withdrawn. One $\mathrm{ml}$ of this suspension ( 2 applications of $0.5 \mathrm{ml}$ each) was dribbled over the roots of each unit of 10 plants. The seedlings were then incubated at $26^{\circ} \mathrm{C}$, and the number of diseased plants was recorded after 6 days.

In several experiments we found that this method provided less variable results than when the entire seedling was sprayed with a suspension of motile zoospores. Also, when mortality was observed at 4 or 7 rather than 6 days, either too few or too many seedlings had died to reveal differences among lines. At 5 days the difference among varieties was less and the variation within varieties was more than at 6 days. Thus, the inoculation of roots alone and 6-day incubation are both important.

Fifty-nine tobacco lines of unknown susceptibility to black shank were tested in three groups of about 20 lines each. The first group, which was inoculated on March 23, also included two standards of known performance in the field: resistant commercial line $\mathrm{L}$ and susceptible commercial line WS-1 17. On April 5, these standards plus highly resistant Florida breeding line FI were included with two other groups in the seedling tests. Since all unknown lines were not in all groups, we calculated their susceptibility relative to the standard susceptible line WS-117 within each group. The number of diseased plants of an unknown line times 100 was divided by the number of diseased WS-117 (See Column 2, Table 4).

RESULTS. Within all three groups of seedlings, fewer resistant L than susceptible WS-117 were diseased, demonstrating the reasonable outcome of the method. Furtleer, in the second and third groups, fewer of the highly resistant F1 were diseased than either resistant $\mathrm{L}$ or susceptible WS-117. Significantly fewer L than WS-117 were diseased in all three groups and significantly fewer FI and L were diseased in the third group.

Turning to a practical question, we now ask whether seedlings from some of the unknown lines appeared more resistant than $\mathrm{L}$, a line which provides useful resistance in the field. The answer is "yes", because 10 of the 59 unknown lines had fewer diseased plants than $\mathrm{L}$, and two of these, 77-15 and 77-53, had significantly fewer. Later we report a field test that included the sixteen selected lines of Table 4. 
Table 4. Seedling and field susceptibility. Seedling susceptibility is 100 times the diseased plants of an unknown line divided by the diseased WS-117 plants in the same test. Field susceptibility is 100 times the diseased plants of an unknown line divided by the diseased WS-117 in the same plot. The $n$ is the number of plots where WS-117 was diseased and hence field susceptibility could be calculated. Seedling value for $L$ is the mean of three groups.

\begin{tabular}{lccl}
\hline line & Seedling & Field & $n$ \\
117 & 100 & 47 & 3 \\
$77-36$ & 72 & 10 & 2 \\
$77-44$ & 72 & 12 & 2 \\
$77-52$ & 72 & 55 & 4 \\
$77-46$ & 70 & 10 & 2 \\
$77-54$ & 68 & 72 & 1 \\
$77-53$ & 62 & 68 & 4 \\
$77-43$ & 50 & 26 & 2 \\
$77-57$ & 50 & 80 & 2 \\
L & 50 & 7 & 1 \\
$77-39$ & 49 & 12 & 1 \\
$77-28$ & 41 & 0 & 1 \\
$77-60$ & 33 & 54 & 4 \\
$77-15$ & 28 & 0 & 1 \\
FI & 14 & 0 & 1 \\
$77-18$ & 4 & 30 & 1 \\
\hline
\end{tabular}

Large plants in the field, 1976.

Although the test of seedlings in the laboratory has advan. tages of control and economy, the payoff comes in the field.

MATERIALS AND METHODS. On May 22, forty-five lines of unknown response and five lines of known response to black shank were planted in an infested field as described under the section on "Response to soil moisture in the field". The five lines of known response to black shank were two selections of the highly susceptible WS-117, the resistant $\mathrm{L}$, the resistant WS-149b, and the highly resistant FI.

RESULTS. At season's end the number of diseased plants in a row was related to mean elevation by regression analysis. The equation, diseased plants per row $=17.0-.99$ $x$ elevation $(\mathrm{cm})$, says that the number of diseased plants per row decreases about I for each $\mathrm{cm}$ of elevation. This equation explains about a third of the variation in disease. In Fig. 4, we have shown the regression line for all the plants and the number of diseased plants for five lines of known response. Susceptible plants should have much more disease for elevation, i.e., be above the regression line, and resistant ones should be below the line.

Four tests of susceptible WS-117 were performed, i.e., two selections in two replicates. In two cases, disease was much more than predicted for the elevation, and the symbol $\mathrm{W}$ in Fig. 4 appears above the regression line. In two cases, WS-1 17 was not diseased because it was at high elevations. Resistant WS-149b, symbol B, had more disease in one case and less in another than predicted for the elevation. Finally, the resistant $\mathrm{L}$ and resistant $\mathrm{Fl}$ had less disease than predicted for the elevation.

The variable performance of WS-149b reduced our confidence in the 1976 field experiment. If the experiment and refinement of disease observations by measurements of elevation could not consistently characterize the well-known WS-149b as either resistant or susceptible, the results for the 45 unknown lines were questionable. Therefore, the efforts to develop the seedling method were increased, and finally in 1977 we experimented in another field and inter- planted susceptible "witnesses" in every row of any test line of tobacco.

Large plants in the field, I977.

MATERIALS AND METHODS. On June 13, twenty-nine lines of shade tobacco and one of broadleaf were planted in Poquonock on twelve bents of a field where black shank had attacked nearly every WS-117 plant two years before. Line $\mathrm{L}$ had been grown on the field in the intervening year, and little disease was seen in this resistant variety. The thirty lines of tobacco included the sixteen listed in Table 4. The lines were arranged in four randomized blocks. Unlike the 1976 experiment, the first and every sixth plant in a varietal row were susceptible WS-I17 plants, which provided the witnesses mentioned above. Thus, each plot had 21 to 23 plants of the variety under test and five WS-117 plants.

On July 18 , black shank was first observed. The plants were observed regularly, and on October 17, the diseased plants were counted.

RESULTS WITH 30 VARIETIES. The mean percentage of diseased plants in four plots as determined on October 17 was transformed to angles before analyzing the variance. Fifteen lines were significantly less susceptible than susceptible standard WS-117, and six lines had less disease than L, but not significantly less.

Among the entries significantly more resistant, i.e., less susceptible than WS-117, were several lines resistant in seedling tests over a 3-year period. They were: Fl; a selection of FI (128); WS-149b; L; a flue-cured tobacco line resistant to black shank in North Carolina (NC 2326); a broadleaf tobacco line resistant to black shank in Maryland (MD 609); a

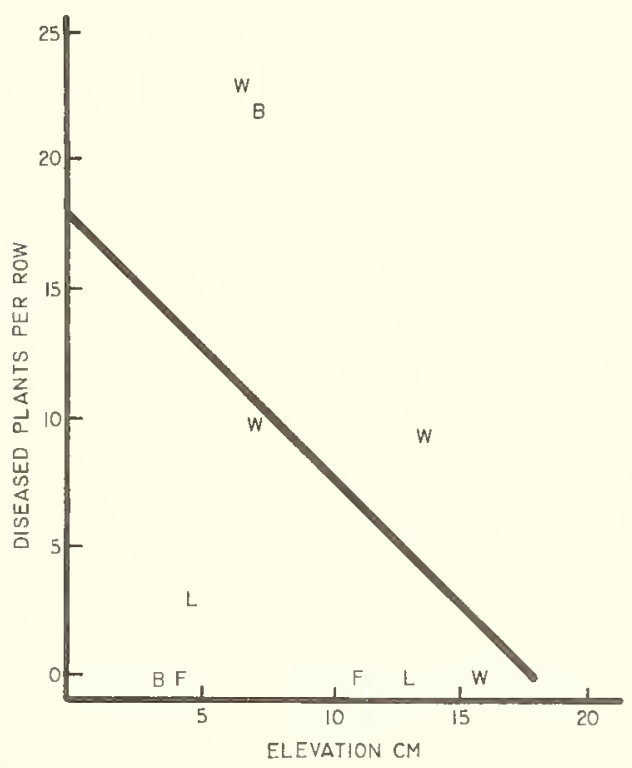

Fig. 4 Diseased plants per $\mathbf{1 0} \mathrm{m}$ of row as a function of elevation above lowest point in the field of 1976 experiment. The regression line drawn on the figure was estimated from 100 observations in two replicates of 45 tobacco breeding lines of unknown and 5 tobacco breeding lines of known resistance. The observations of the two replicates of 5 known tobacco breeding lines are shown by $W$ (WS-117), L, 8 (WS-149b), and $F(F I)$. 
Table 5. The percentage of diseased plants among 16 lines in four blocks in 1977. The numerator shows the disease among the tested line, and the denominator shows the disease among the WS-117 witnesses in the same plot. The blocks are identified as A, B, C, and $\mathrm{D}$.

\begin{tabular}{lcccc}
\hline & \multicolumn{5}{c}{ Disease is \% in tested/\% in WS-117 } \\
Line & $\mathrm{A}$ & $\mathrm{B}$ & $\mathrm{C}$ & $\mathrm{D}$ \\
\hline WS-117 & $0 / 0$ & $17 / 60$ & $27 / 40$ & $37 / 80$ \\
$77-60$ & $21 / 40$ & $4 / 20$ & $5 / 20$ & $48 / 40$ \\
$77-43$ & $0 / 20$ & $23 / 50$ & $0 / 0$ & $4 / 60$ \\
$77-57$ & $0 / 0$ & $32 / 40$ & $4 / 0$ & $48 / 60$ \\
$\mathrm{~L}$ & $0 / 0$ & $0 / 0$ & $0 / 0$ & $4 / 60$ \\
$77-18$ & $0 / 0$ & $0 / 0$ & $15 / 50$ & $4 / 0$ \\
$77-39$ & $19 / 0$ & $5 / 40$ & $0 / 0$ & $0 / 0$ \\
$77-28$ & $0 / 0$ & $0 / 0$ & $12 / 0$ & $0 / 80$ \\
$77-36$ & $0 / 0$ & $9 / 80$ & $0 / 0$ & $4 / 40$ \\
$77-44$ & $0 / 20$ & $5 / 20$ & $0 / 0$ & $0 / 0$ \\
$77-52$ & $17 / 25$ & $29 / 40$ & $9 / 20$ & $14 / 40$ \\
$77-15$ & $10 / 0$ & $0 / 20$ & $0 / 0$ & $0 / 0$ \\
$77-46$ & $0 / 20$ & $4 / 20$ & $0 / 0$ & $0 / 40$ \\
FI & $0 / 0$ & $0 / 0$ & $0 / 20$ & $0 / 0$ \\
$77-54$ & $18 / 25$ & $5 / 0$ & $10 / 0$ & $5 / 0$ \\
$77-53$ & $21 / 0$ & $22 / 20$ & $4 / 17$ & $54 / 80$ \\
\hline
\end{tabular}

highly resistant line from South America (Beinhart 1000-1); and a line developed from WS-149b (ACC 75).

FIELD SUSCEPTIBILITY VS. SEEDLING SUSCEPTIBILITY. Among the 30 lines were 16 whose seedling susceptibility had been appraised as shown in Column 2 of Table 4. We now examine their disease susceptibility in the field.

Black shank disease among the 16 lines can be judged against disease in the WS-117 witnesses planted in the same rows. In Table 5, we show the percentage of disease among the 16 lines in the four plots as a numerator divided by the percentage of disease among the five witness WS-117 plants in each plot. Within the sixteen lines we asked whether a WS-117 witness within each plot reduced variability and whether seedling resistance clearly predicted susceptibility in the field.

Witnesses. The disease among the WS-117 witnesses explains $35 \%$ of the variability in the tested lines (Fig. 5). Disease in a tested line increased $31 \%$ as much as that in WS-117. It is logical that the regression practically goes

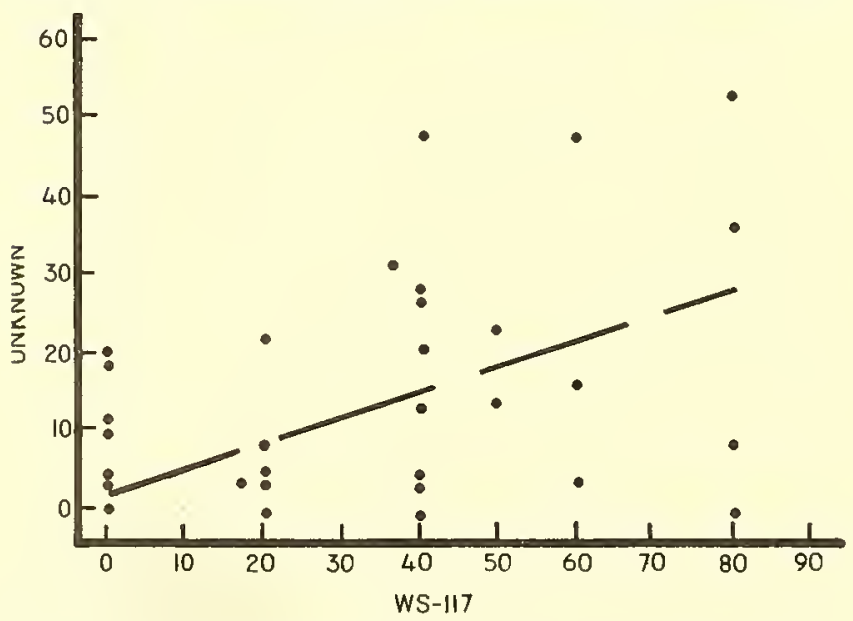

Fig. 5 The percentage of diseased plants among sixteen lines in four field plots in 1977 as a function of the disease among witness WS-117 plants in the same plot. (Note 0 is moved to show observations of 0 disease). Fewer than 64 points show because of duplicates, especially $(0,0)$. through the origin: i.e., no disease in WS-117, no disease in tested line

A further examination of the witnesses, however, reveals that their testimony cannot be taken on faith as an appraisal of the initial inoculum in the soil. Planted among other WS- 117 in four plots the witness WS- 117 was 0, 40, 60, and $80 \%$ diseased, while among eight plots of resistant $\mathrm{L}$ and $\mathrm{F} 1$ lines it was only $0,0,0,0,0,0,20$ and $60 \%$ diseased. WS-117 had more disease among susceptible than among resistant neighbors.

The influence of neighbors upon the amount of disease is well-known. For example, when a "multiline" mixture of resistant and susceptible varieties is grown, disease is decreased markedly (Browning and Frey, 1969). Evidently the amount of disease in WS-117 could be held in check somewhat by mixing it with a resistant line like $\mathrm{L}$. This is a practical result.

Our view of using WS-117 as an indicator, however, became clouded as we wondered whether WS-117 was indicating the soil and inoculum as we hoped or the surrounding variety. We reasoned through this problem.

Mathematical analysis of witnesses. The field was planted to many u plants, i.e., test or unknown lines, and a few w plants, i.e., WS-1 17. Disease (W) in the w plants and disease $(\mathrm{U})$ in the $u$ plants increased the number $(\mathrm{N})$ of pathogenic propagules per $u$ plant. Disease $W$ and $U$ are the diseased plants per total $w$ or u plants at time T.

After $T$ days the disease $W(T)$ is a sum, or integral, of infections during time $T$ if latency or time from infection to symptom is short relative to $T$.

$$
W(T)=K \int_{0}^{T} N_{W}(t) d t
$$

$\mathrm{K}$ is $w$ plants diseased per propagule per day. $\mathrm{N}_{\mathrm{W}}(\mathrm{t})$ is propagules per $w$ plants at time t. The dimensions of equation (1) are

Plants cliseased $=$ plants diseased $x$ propagule $\mathrm{x}$ day

$$
\text { plants propagule day plant }
$$

Similarly, disease in the unknown lines of $u$ plants is

$$
U(T)=k \int_{0}^{T} N_{u}(t) d t
$$

where $\mathrm{k}$ is u plants diseased per propagule per day.

If the inoculum or propagules that cause the disease observed are from the initial infestation in the soil plus an increment contributed by neighboring plants and if re-infection of a plant by propagules from itself is insignificant, analysis is simplified. Since the immediate neighbors of $\mathrm{w}$ plants are all $u$ plants and since five of six immediate neighbors of $u$ plants are other $u$ plants, the inoculum $\mathrm{N}_{\mathrm{u}}(\mathrm{t})$ and $\mathrm{N}_{w}(t)$ around $w$ and $u$ are nearly the same.

Thus,

$$
W(T) / K=U(T) / k=\int_{j}^{T} N_{W}(t) d t=\int_{j}^{T} N_{u}(t) d t
$$

or simply

$U(T) / W(T)=k / K$ 
Thus, W(T) is an honest witness in the sense that the ratio of $\mathrm{U}$ to $\mathrm{W}$ where $\mathrm{W}$ is not zero shows the susceptibility $\mathrm{k}$ of an unknown line relative to the standard susceptibility $\mathrm{K}$ of WS-117. Accordingly, we have calculated $100 \mathrm{U}(\mathrm{T}) / \mathrm{W}(\mathrm{T})$ in the $n$ plots of each line where $\mathrm{W}(\mathrm{T})$ was not zero, and tabulated it as "Field susceptibility" in the third column of Table 4.

Alternatively, the 64 observations of $U$ can all be analyzed, using disease in the witness plants as a covariate.

Prediction of susceptibility in the field by the test of seedling susceptibility. The sixteen lines are arranged in Table 4 from most to least seedling susceptibility. If seedling susceptibility predicts field susceptibility, the field susceptibility in column 3 of Table 4 should decrease from top to bottom in the table. In the case of the three standard varieties this is true: WS-117 is more susceptible at 47 than $\mathrm{L}$ at 7 and than $\mathrm{Fl}$ at 0 .

Unfortunately, the field susceptibility of the thirteen unknown lines does not decrease regularly from top to bottom in the table, and we must conclude that seedling resistance is an imperfect predictor of resistance in the field.

Nevertheless, we remember that the seedling test did show the known field resistance of $\mathrm{L}$ and $\mathrm{FI}$, and it is profitable to look for other lines resistant in both seedling and field tests. In fact, lines 77-15, 77-28, and 77-39 appeared resistant in both tests, a promising clue to future resistant varieties.

\section{RESISTANCE IN BROADLEAF TOBACCO.}

Generally, Connecticut farmers who grow broadleaf do not grow shade tobacco and do not use fields used for shade tobacco. To date, black shank has not been found in commercial plantings of broadleaf tobacco in Connecticut. Since, however, the disease can be expected eventually to appear in fields of broadleaf, the susceptibility of broadleaf tobacco needs to be known. Al though broadleaf tobacco has no clear varieties or cultivars, seed stocks maintained by various growers do differ in such characteristics as earliness and number and width of leaves. Since the standard K broadleaf seed was always highly susceptible in seedling tests, we tested other selections of broadleaf seed in the field.

\section{Materials and methods.}

On June 14, 1977, broadleaf tobacco from seven lots of seed from various growers was tested with two susceptible shade lines and one resistant shade line. They were planted in part of the field described in the section, "Large plants in the field, 1977". Plots of each lot were rows $10 \mathrm{~m}$ long. There were three randomized blocks. Plants were observed regularly, and on August 19 diseased plants were finally counted.

RESULTS. Witness WS-1 17 plants were 25 to $75 \%$ diseased in all but 4 of the 30 plots, showing the uniform distribution of the pathogen. The seven lots of broadleaf tobacco and the two susceptible shade lines were 28 to $41 \%$ diseased; while the resistant shade line ACC-75 was only $2 \%$ diseased. Evidently, broadleaf tobacco is generally susceptible to black shank in Connecticut.

\section{DISCUSSION AND CONCLUSIONS}

Black shank of tobacco, caused by the fungus Phytophthora parasitica Dast. var. nicotianae (B. de Haan) Tucker has long been considered a warm climate disease of no concern to Connecticut growers. However, in 1973, the disease did appear in Connecticut fields. We have now determined that the fungus present in Connecticut is a new race, race 3 , but we do not know its origin. Race 3 differs from the Southern races 0 and $I$ by a) tolerating colder soil temperatures, b) differentially infecting standard tobacco cultivars, and c) displaying differences in metabolism (Mclntyre \& Taylor, 1978, McIntyre \& Hankin, 1977).

Since the disease has reappeared every year since its discovery, some control measures are necessary. Fumigant chemicals in the soil have been effective at high rates (280 1/ha). Fumigants containing chloropicrin reduced disease in Connecticut as they have in Southern states, but they reduced leaf quality to an unacceptable level for Connecticut cigar-wrapper tobacco. The fumigant DD-MENCS (vorlex) does not contain chloropicrin, is often used as a control for the tobacco cyst nematode, and did reduce black shank when used at the higher than normal rate of $280 \mathrm{l} / \mathrm{ha}$ ). A slight reduction in quality was noted. For economic reasons, however, resistant varieties may be the best approach to control.

Although the cigar-wrapper variety $L$, grown commercially for a decade, tolerates black shank in Connecticut fields, the horticultural features of $\mathrm{L}$ do not suit the needs of al] growers. Other resistant varieties, therefore, are needed. To develop such varieties, one must be able to test reliably for resistance to black shank. Preferably an early test should be as compact and as brief as possible, minimizing space and time needed for the necessary field evaluation.

Various methods have been devised to determine resistance or susceptibility in young plants in the laboratory (Litton, et al. 1970). None are ideal. Results reported in this bulletin suggest that the rapid method of Mclntyre and Taylor works reasonably well when a) only the roots of small seedlings are inoculated, b) the inoculum is kept as uniform as possible by stirring encysted zoospores, and c) one uses a standard period of time between inoculation and recording of data. Lines with a long history of resistance or susceptibility in the field or in several types of tests for young plants were well distinguished in the seedling stage, thus showing the method to be reasonable.

Some aspects of the test, however, are still not understood. We were unable to get a high correlation between the seedling and field response for all entries in thirteen lines with unknown resistance to black shank. Among thirteen unknowns, two in particular appeared resistant in the seedling test, but not in the field test (Table 4). Only one appeared susceptible as a seedling but resistant in the field. Thus, one is reasonably confident that a line susceptible as a seedling would be susceptible in the field and need not be tested in the field. One is less confident that lines resistant as a seedling will be resistant in the field. 
Although field testing is certainly the final criterion, many variables may interfere with a clear indication of resistance. Results we report here indicate that variations in elevations of the soil within a plot influence the outcome. Low areas where water stands or runs after rains and high areas with good drainage mask practical differences in resistance. By measuring the elevations, some variability can be accounted for, but other factors also operate in the field.

We attempted to account for variability of inoculum potential from spot to spot in the field by including a known susceptible line as a witness in the row of a line under test. Disease in the witness did improve discrimination of resistance even though disease in the witness was modified by the resistance of its neighbors. A similar phenomenon for other diseases is known as multi-line resistance, and mixing resistant with susceptible plants evidently would decrease black shank in the susceptible.

We conclude that the search for resistant germ plasm is important since chemical control is expensive and may affect quality of the crop. A successful field test requires a) a level field with moist soil and irrigation when necessary, b) infestation and previous cropping with a susceptible variety, c) witnesses, and d) replications to reduce effects of unknown variables. Highly susceptible lines have been detected as seedlings, and confidence in the prediction of field response would surely improve by repeating seedling tests. Despite these difficulties, the promising line ACC-75 was developed by testing resistance in the secdling stage, and it was grown commercially in 1977.

The results reported in this bulletin will, we hope, hasten attainment of the goal of safely and economically controlling black shank in Connecticut.

\section{Ack nowledgements}

We wish to thank Drs. H.C. De Roo and George Stephens for the measurements of soil surface contours in the 1976 field studies. We also thank the Brown Tobacco Company and H.C. Thrall and Sons for use of their fields, equipment, and personnel in growing and processing tobacco used in these studies and Robert Borg. Jr. for applying the fumigants. Jill Morse and Lila DeRobertis provided excellent technical assistance.
Literature Cited

Browning, J.A. and K.J. Frey. 1969. Multiline cultivars as a means of disease control. Ann. Rev. Phytopath. 7:355-382.

Campbell, W.A. 1949. A method of isolating Phytophthora cinnamolli directly from soil. Plant Dis. Reptr. 33:134-135.

Goode, P.M. 1956. Infection of strawberry roots by zoospores of Phyto phthora fragariac. Brit. Mycol. Soc. Trans. 39:367-377.

Grimm, G.R. and A.F. Alexander. 1973. Citrus leaf pieces as traps for Phytophthora parasitica from soil slurries. Phytopath. 63:540-541.

Litton, C.G., G.B. Collins, and P.D. Legg. 1970. A greenhouse technique for screening tobacco seedlings for black shank resistance. Tob. Sci. 14:124-125.

Lucas, G.B. 1965. Diseases of Tobacco. Scarecrow Press, Inc., N.Y., N.Y.

Mclntyre, J.L. and G.S. Taylor. 1976. Screening tobacco seedlings for resistance to Phytophthora parasitica var, nicotianae. Phytopath. 66:70-73.

Mclntyre, J.L. and L. Hankin. 1977. Lack of kestose (fructosylsucrosel production by Race 3 of Phytophthora parasitica var. nicotianae differentiates it from Races 0 and 1. Mycologia 69:756-760.

Mclntyre, J.L. and G.S. Taylor. 1978. Race 3 of Phytophthora parasitica var. nicotianae. Phytopath 68:35-38.

Taylor, G.S. 1975. Cold tolerance of Phytophthora parasitica var. nicotianae isolated from tobacco in Connecticut. Plant Dis. Reptr. 59:249-252.

Taylor, G.S., P.M. Miller, and J.L. Mcintyre. 1975. Chemical control of tobacco black shank in Connecticut. Plant Dis. Reptr. 59:434-438.

Tavlor, G.S. 1978. Rapid production of Phytophthora parasitica var. nicotianae zoospores in vitro from infested cloth. Plant Dis. Reptr. 62:

Todd, F.A. 1973. Tobacco disease control practices for 1974. In Tobacco Information for 1974. N.C. Agric. Ext. Ser. Misc. Publ. No. 108.

Tsao, P.H. and G. Ocana. 1969. Selective isolation of species of Phytophthora from natural soils on an improved antibiotic medium. Nature 233:636-638.

Walton, Gerald S. and Saul Rich. 1974. Serious and unusual plant diseases in Connecticut in 1973. Plant Dis. Reptr. 58:428-429. 

$\begin{array}{ll}\text { University of } & \text { Connecticut } \\ \text { Libraries }\end{array}$ 
